\title{
Copper-inducible transcriptional regulation at two promoters in the Escherichia coli copper resistance determinant pco
}

\author{
D. A. Rouch and N. L. Brown
}

Microbial Molecular Genetics and Cell Biology Research Group, School of Biological Sciences, The University of Birmingham, Edgbaston, Birmingham B15 2TT, UK
Author for correspondence: N. L. Brown. Tel: +44 121414 5467. Fax: +44 1214145907. e-mail: N.L.Brown@bham.ac.uk

The pco determinant of Escherichia coli plasmid pRJ1004 encodes inducible resistance to the trace element copper. The identification of two copperdependent transcriptional initiation regions within pco that each contain a similar upstream hyphenated dyad motif is described. Deletion constructs showed that this 'copper box' motif was essential for copper-inducible activity at both pco promoters, PpcoA and PpcoE. The placement of the motif differs in the two promoters, and PpcoA contains an extended -10 nonamer typical of promoters for which RNA polymerase does not bind specifically to -35 sequences. PpcoE does not contain this motif and is the more strongly expressed promoter. The transcript from PpcoA contains the pCOABCDRS genes, while PpCoE expresses only pcoE. The induction profiles for PpcoA- and PpCoE-lacz fusions were flattened sigmoidal curves with a gradual response to increasing copper concentration. On high-copy-number plasmids, zinc was found also to induce transcription from both promoters in vivo. Both promoters showed inducible activity in the absence of pcoRS, the plasmidborne two-component regulatory system, indicating that a second trans-acting regulatory system is present on the chromosome. The pcoR product showed repressor action in the absence of pcos, while still allowing induction, suggesting the chromosome encoded a similar two-component system to pco. TnphoA insertion mutagenesis identified chromosomal genes which affected promoter expression, including ptsH, ptsl (sugar phosphotransferase system) and cya (adenylate cyclase). The results support that idea that pco-encoded copper resistance is an auxiliary mechanism for handling copper, the regulation of which is integrated with the chromosomal regulation of cellular copper metabolism.

Keywords : copper resistance, plasmid, gene regulation, trace element, homeostasis

\section{INTRODUCTION}

Microbial resistance to a wide range of toxic metal ions has been reported. This includes resistance to metals that are purely toxic, with no ascribed biological function, such as mercury and cadmium, and to metals that are toxic in excess but are required in small amounts for biological activities, such as copper and zinc (Silver, 1992; Silver \& Ji, 1994). A study of the cellular response to such toxic but essential metals is necessary in

Abbreviation: CAT, chloramphenicol acetyltransferase. understanding the mechanisms of metal ion homeostasis (Lee et al., 1990; Rouch, 1986).

Plasmid-encoded resistance to copper has been documented in a number of species, the best studied of which are Escherichia coli (Tetaz \& Luke, 1983), Pseudomonas syringae pv. tomato (Bender \& Cooksey, 1986) and Xanthomonas campestris pv. juglandis (Stall et al., 1986), and copper resistance has been reviewed (Brown et al., 1993, 1992; Cervantes \& Gutierrez-Corona, 1994; Cooksey, 1993, 1994). The conjugative plasmid pRJ1004 confers copper resistance and was isolated from E. coli in the gut flora of pigs fed a diet supplemented with copper sulphate as a growth promotant (Tetaz \& Luke, 
1983). The copper resistance specified by this plasmid involves the $p c o$ gene cluster, which contains seven genes, pcoABCDRSE (Brown et al., 1995; Lee et al., 1990). Copper resistance in P. syringae pv. tomato is specified by the cop determinant, which contains six genes, copABCDRS, arranged in a single operon, homologous to the equivalent $p c o$ genes (Brown et al., 1995; Cooksey, 1994; Silver et al., 1993). The sequence of a plasmid-borne resistance determinant from $X$. campestris pv. juglandis has also been analysed, and contains genes homologous to both $p c o A B C D$ and copABCD (Lee et al., 1994). In the last two examples resistance is likely to have been selected due to the use of copper-containing antimicrobial formulations on vegetable crops where these phytopathogenic bacteria occur.

In all three cases copper resistance has been shown to be inducible (Mellano \& Cooksey, 1988; Rouch et al., 1985; Voloudakis et al., 1993). The pco and cop determinants specify regulatory systems, $p c o R S$ and $\operatorname{cop} R S$, respectively, which show sequence similarity to other two component systems (Parkinson, 1993; Parkinson \& Kofoid, 1992) in which R (receiver) gene products are transcriptional regulators that receive control information from the $S$ (sensor) gene products. An additional sensor gene $p c o S^{*}$ may be encoded by second-site translation initiation within $p c o S$. Both the $p c o R$ and $\operatorname{cop} R$ regulatory gene products are class 2 receivers by the homology typing scheme (Pao et al., 1994): this class also includes OmpR, PhoB, VirG and the Streptomyces lividans chromosomal copper-responsive gene CutR (Tseng \& Chen, 1991). CopR has been shown to bind to an upstream motif in the Pseudomonas copABCD promoter region (Mills et al., 1994). The regulatory genes for the $X$. campestris pv. vesicatoria cop determinant are not yet known (Lee et al., 1994). We have predicted that bacterial resistance to copper should be expressed in relation to the external concentration of this trace element, to maintain copper ion homeostasis (Lee et al., 1990).

We report here the transcriptional characterization of the regulatory system that controls the inducible expression of $p c o$-encoded copper resistance. Two architecturally different promoters with copper-dependent cis control elements were identified within the $p c o$ determinant, which are under trans control from both plasmid and chromosome. Transposon mutagenesis showed that mutations in the $p t s H I$ and $c y a$ genes affect expression of the $p c o$ promoters.

\section{METHODS}

Bacterial strains, plasmids and media. Bacterial strains used were E. coli $\mathrm{K}-12$ derivatives; TG2 ( lac-pro supE thi hsdD5

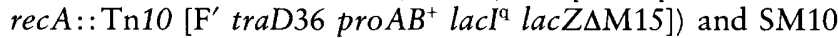
(thi thr leu tonA lacY supE recA::RP4-2-TC::Mu) (Taylor et al., 1989). Plasmids used in this study are shown in Table 1 , and inserts of recombinant plasmids used are shown in Figs 1 and 2. Plasmid pMU2385 allows promoter sequences to be identified at low copy number by plate assay for lacZ expression, avoiding problems of titration of regulators associated with high-copy-number reporter plasmids. Plasmid pKK232.8 is medium copy number; it was used for ease of genetic manipulation and for more precise assay of promoter activity (by initial rate activity of chloramphenicol acetyltransferase) than is possible with the lac $Z$ reporters.

LB, LA and copper-containing media were made as described elsewhere by Rouch et al. (1985). HA contained $\left(1^{-1}\right): 8 \mathrm{~g}$ tryptone, $4 \mathrm{~g} \mathrm{NaCl}$ and $15 \mathrm{~g}$ agar; similarly for soft HA except $6 \mathrm{~g}$ agar. Standard additions were $\left(\mu \mathrm{g} \mathrm{ml}^{-1}\right)$ : carbenicillin, 250; tetracycline, 25; trimethoprim, 25; kanamycin, 50; X-Gal, 40. $\mathrm{CuSO}_{4}$ and $\mathrm{ZnSO}_{4}$ were ultrapure grade (Aldrich); for induction a stock solution of $\mathrm{CuSO}_{4}(20 \cdot 0 \mathrm{mM})$ in $\mathrm{LB}, \mathrm{pH} 7 \cdot 5$, was diluted as appropriate. In quantitative copper response assays, copper was removed from broth, or agar in molten form, by twofold treatment with $0 \cdot 1 \%(\mathrm{w} / \mathrm{v})$ Chelex -100 resin (Bio-Rad) for $1 \mathrm{~h}$ prior to the addition of $\mathrm{CuSO}_{4}$ and trace element solution [as for Neurospora Minimal Medium (Daggett et al., 1982) except without copper and zinc].

Recombinant DNA techniques. DNA manipulations were performed according to Sambrook et al. (1989). Vent DNA polymerase (New England Biolabs) was used according to the supplier's instructions in all PCR experiments, due to its proof-reading capability. The identities of cloned PCR products were verified by DNA sequencing.

Isolation of promoter-lac fusions. Fragments of a Sau3AI digest of pPA87 were ligated into pMU2385, transformed into TG2(pPA87) and plated on LA containing ampicillin, trimethoprim, X-Gal and $0.8 \mathrm{mM} \mathrm{CuSO}$. Dark blue colonies were replicated onto LA containing carbenicillin, trimethoprim and X-Gal. Recombinants showing copper-inducible $\beta$ galactosidase activity (i.e. dark blue in the presence of copper, light blue or colourless in its absence) were identified. Plasmids from these recombinants were transformed into TG2 to separate the promoter-fusion plasmids from pPA87. Trimethoprim-resistant transformants were selected and their plasmid DNA was isolated for nucleotide sequence analysis.

Construction of full and truncated promoter (-cat, -lacZ) fusions. Oligonucleotide primers were designed to give PCR products from pPA87, which were cloned into the filled-in HindIII site of pKK232.8. The fragments generated are described in the legend to Fig. 2, numbered according to the nucleotide sequence reported in Brown et al. (1995). The $\mathrm{A}(\mathrm{box}-35-10)$ and $\mathrm{E}(\mathrm{box}-35-10)$ PCR products were also cloned into the SmaI site of pMU2385, to give pMUA and pMUE, respectively. Recombinants were chosen with fragments orientated with the -10 ends closest to the reporter genes of the vectors.

Construction of pco-lux fusions. The A(box - 35-10) PCR product, pco 128-291, was cloned into the SmaI site of pUCD615, to form pLUXA. pLUXAR was formed by cloning the end-filled $5 \cdot 1 \mathrm{~kb}$ HindIII-BglII fragment of pR 5 into the SmaI site of pUC19, and cloning the resulting HindIII (filled)-XbaI fragment into pUCD615 digested with SmaI and $X b a I$. Construction of pLUXBR was initiated with ligation of the end-filled $2.5 \mathrm{~kb} S p h \mathrm{I}-B g l \mathrm{II}$ fragment of pR5 (S. R. Barrett $\&$ N. L. Brown, unpublished) into the $S m a$ I site of pBluescript $\mathrm{SK}(+)$, followed by cloning of the resulting $\mathrm{SacI}$ (filled) $-X b a \mathrm{I}$ fragment into SmaI/XbaI-digested pUCD615. Plasmid pR5 is a pPA87 derivative in which the non-unique $R$ srII site in wildtype $p c o R$ had been replaced by a unique $B g l$ II site. pA5, containing the $5^{\prime}$ end of $p c o$, resulted from ligation of the $0.7 \mathrm{~kb}$ HindIII-KpnI fragment from pPA173 into pSU19: this vector was chosen since it is compatible with pUCD615. 
Table 1. Plasmids used in this study

\begin{tabular}{|c|c|c|c|}
\hline Plasmid & pco region & Relevant features $\dagger$ & Source or reference \\
\hline pKK232.8 & - & bla, cat reporter; medium copy number & Brosius \& Holy (1984) \\
\hline pMU2385 & - & galK-lacZ reporter, $\mathrm{T} \mathrm{p}^{\mathrm{r}}$; low copy number & Praszkier et al. (1992) \\
\hline pRT733 & - & bla, $\operatorname{Tn} p h o A$ suicide vector & Taylor et al. (1989) \\
\hline pBluescript $\mathrm{SK}(+)$ & - & $b l a$, cloning vector & Stratagene \\
\hline pUC19 & - & bla, cloning vector & Yanisch-Perron et al. (1985) \\
\hline pSU19 & - & cat, cloning vector & Bartolomé et al. (1991) \\
\hline pPA87 & PCOABCDRSE & $\begin{array}{l}12.5 \mathrm{~kb} \text { HindIII fragment from } \mathrm{pRJ} 1004 \text { in } \\
2 \times \mathrm{pBR} 322\end{array}$ & Rouch (1986) \\
\hline pPA173 & pCOABCDRSE & $\begin{array}{l}9 \mathrm{~kb} B g l \mathrm{II}-H i n \mathrm{dIII} \text { fragment from pPA87 } \\
\text { in pMU } 530\end{array}$ & Rouch (1986) \\
\hline pR5 & pcoABCDRSE & $\begin{array}{l}9 \mathrm{~kb} B g l \mathrm{II}-H i n d I I I \text { fragment from pPA173 } \\
\text { in pACYC184 }\end{array}$ & $\begin{array}{l}\text { S. R. Barrett \& N. L. Brown, } \\
\text { unpublished }\end{array}$ \\
\hline pMUE23 & $\mathrm{P} p c o E$ & $0.24 \mathrm{~kb}$ Sau3AI insert in pMU2385 & This study \\
\hline $\mathrm{pA}$ & $\mathrm{PpcoA}$ & PCR product in pKK 232.8 & This study \\
\hline $\mathrm{pA}(\mathrm{box}-35-10)$ & $\mathrm{P} p c o A$ & PCR product in $\mathrm{pKK} 232.8$ & This study \\
\hline $\mathrm{pA}(-35-10)$ & Truncated $\mathrm{P} p c o A$ & PCR product in $\mathrm{pKK} 232.8$ & This study \\
\hline $\mathrm{pA}(-10)$ & Truncated $\mathrm{P} p c o A$ & PCR product in pKK 232.8 & This study \\
\hline $\mathrm{pE}$ & $\mathrm{P} p c o E$ & PCR product in $\mathrm{pKK} 232.8$ & This study \\
\hline $\mathrm{pE}(\mathrm{box}-35-10)$ & $\mathrm{P} p c o E$ & PCR product in pKK 232.8 & This study \\
\hline $\mathrm{pE}(-35-10)$ & Truncated $\mathrm{P} p c o E$ & PCR product in $\mathrm{pKK} 232.8$ & This study \\
\hline $\mathrm{pE}(-10)$ & Truncated PpcoE & PCR product in $\mathrm{pKK} 232.8$ & This study \\
\hline pUCD615 & - & lux $C D A B E$, bla, $\mathrm{Km}^{\mathrm{r}}$; high copy number & Rogowsky et al. (1987) \\
\hline pLUXAR & $p c o A B C D R$ & $\begin{array}{l}5 \cdot 1 \mathrm{~kb} \text { HindIII-BglII fragment from pR5 in } \\
\text { pUCD615 }\end{array}$ & This study \\
\hline pLUXBR & $p c o B C D R$ & $\begin{array}{l}2 \cdot 5 \mathrm{~kb} S p h \mathrm{I}-\mathrm{Bg} g \mathrm{II} \text { fragment from } \mathrm{pR} 5 \text { in } \\
\text { pUCD615 }\end{array}$ & This study \\
\hline pLUXA & $\mathrm{P} p c o A$ & PCR product in pUCD615 & This study \\
\hline pA5 & pco $5^{\prime}$ region & $\begin{array}{l}0.7 \mathrm{~kb} \text { HindIII-KpnI fragment from pPA } 87 \\
\text { in pSU19 }\end{array}$ & This study \\
\hline pMUA & $\mathrm{P} p c o A$ & PCR product in pMU2385 & This study \\
\hline pMUE & $\mathrm{PpcoE}$ & PCR product in pMU2385 & This study \\
\hline pPA256 & $p c o R S S^{*} E$ & $\begin{array}{l}3.5 \mathrm{~kb} \text { EcoRV fragment from pPA87 } \\
\text { pBR322 }\end{array}$ & Rouch (1986) \\
\hline
\end{tabular}

† Km, kanamycin; Tp, trimethoprim.

Reporter activities. Chloramphenicol acetyltransferase (CAT) activities from pKK232.8 and its derivatives were assessed in three ways.

(i) Growth rate assay. Overnight cultures in LB were diluted $1 / 100$ in the same media, with or without the addition of $0.6 \mathrm{mM} \mathrm{CuSO}_{4}$, and grown at $37{ }^{\circ} \mathrm{C}$ with shaking for $30 \mathrm{~min}$ prior to addition of chloramphenicol to $25 \mu \mathrm{g} \mathrm{ml}^{-1}$. Incubation was continued and $\mathrm{OD}_{600}$ was monitored at $30 \mathrm{~min}$ intervals for at least $3 \mathrm{~h}$. Growth rates were calculated as $\Delta \log \left(\mathrm{OD}_{600}\right)$ $\mathrm{min}^{-1}$, standardized as percentages of the standard growth rate in LB without chloramphenicol.

(ii) MIC assay. Overnight cultures in LB were diluted $1 / 100$ in $0.85 \%$ saline, $1.0 \%$ glycerol. Duplicate aliquots were placed in flat-bottomed 96-well plates and replicated onto solid media using a steel-pin replicator (Sigma). The media were LA containing chloramphenicol from 0 to $400 \mu \mathrm{g} \mathrm{ml}^{-1}$ in twofold steps, with or without the addition of $0.6 \mathrm{mM} \mathrm{CuSO}_{4}$ or $\mathrm{ZnSO}_{4}$. The presence or absence of growth was measured after 16 and $36 \mathrm{~h}$. Assays were performed three times and the means calculated. (iii) Enzymic assay. Overnight cultures in LB were diluted 1/100 in $10 \mathrm{ml} \mathrm{LB}$, with or without $0.6 \mathrm{mM} \mathrm{CuSO}_{4}$, and grown to an $\mathrm{OD}_{600}$ of approximately 0.5 . Cultures were then centrifuged and resuspended in $1.5 \mathrm{ml}$ assay buffer $(0 \cdot 1 \mathrm{M}$ Tris $/ \mathrm{HCl}$, $\mathrm{pH} 7 \cdot 8$ ), sonicated and centrifuged to remove cellular debris. CAT activities of cell extracts were determined in triplicate by a spectrophotometric method (Shaw, 1975).

$\beta$-Galactosidase activity from pMU2385 and derivatives was determined according to (Miller, 1972). Overnight cultures in LB were diluted $1 / 100$ in the same media with various concentrations of added $\mathrm{CuSO}_{4}$, grown for $2 \mathrm{~h}$ at $37^{\circ} \mathrm{C}$ and assayed in triplicate.

Light output from pUCD615 and derivatives was measured directly with a Biocounter M $1500 \mathrm{P}$ (Lumac) at room temperature $\left(22^{\circ} \mathrm{C}\right)$. Overnight cultures in $\mathrm{LB}$ were diluted $1 / 50$ in the same media, with or without $0.6 \mathrm{mM} \mathrm{CuSO}_{4}$ and grown for $1.5 \mathrm{~h}$ at $37^{\circ} \mathrm{C}$. Samples $(0.1 \mathrm{ml})$ were taken and placed on ice for $10 \mathrm{~min}$, warmed to room temperature for $5 \mathrm{~min}$, then assayed in triplicate. 
TnphoA mutagenesis. Overnight cultures $(0.5 \mathrm{ml})$ of the donor, SM10(pRT733), and recipient, TG2(pMUE23), were centrifuged, resuspended together in $0.3 \mathrm{ml} \mathrm{LB}$ with $0.2 \%$ glucose, plated on LA and incubated at $30^{\circ} \mathrm{C}$ for $2-5 \mathrm{~h}$. Cells were resuspended with three $\times 1 \mathrm{ml} \mathrm{LB}$ and $0.1 \mathrm{ml}$ aliquots were plated on $\mathrm{HA}$ with $0.2 \%$ glucose, trimethoprim, tetracycline and kanamycin, with or without $0.4 \mathrm{mM} \mathrm{CuSO}_{4}$, and incubated at $37^{\circ} \mathrm{C}$ overnight. The plates, with $200-300$ colonies, were overlaid with soft HA containing X-Gal, with or without $0.4 \mathrm{mM} \mathrm{CuSO}$. Plates without copper were examined for derepressed blue colonies at $4-6 \mathrm{~h}$ and plates with copper were examined for super-repressed white colonies overnight. This procedure was performed a number of times. Putative positive colonies were purified and the pMU23 reporter plasmids were checked for integrity by restriction enzyme digestion; plasmids were retransformed into TG2 to test for wild-type inducibility.

The sequence location of $\operatorname{Tn} P h o A$ insertions was determined from templates derived from inverse PCR of chromosomal DNA (Ochman et al., 1988), using primers JL37 (ATATTACTGCACCCGGCGGT) and JL07 (GTAATATCGCCCTGAGCAGC) which match to positions 82-101 and the complement of 59-88 in the TnphoA sequence (Manoil \& Beckwith, 1985), respectively.

Copper response profile analysis. Fitted lines were calculated from the data, after subtracting the basal level of activity (at zero added $\mathrm{CuSO}_{4}$ ), with the aid of a Hill plot (Hill, 1913). For a sigmoidal response, the data points in the mid-response range lie on a straight line, the apparent Hill coefficent $(H)$ being equal to the slope of this line. The fitted curves were derived from the equation:

$Y_{p_{i}}=\left(\left[\mathrm{Cu}_{\mathrm{i}}\right] \mathrm{H} /\left(\left[\mathrm{Cu}_{\mathrm{i}}\right]^{\mathrm{H}}+\left[\mathrm{Cu}_{0.5}\right]^{\mathrm{H}}\right)\right) \times \mathrm{Y}_{\max }+Y_{\mathrm{b}}$

where $Y_{p_{i}}$ is the predicted $\beta$-galactosidase activity at copper concentration $i,\left[\mathrm{Cu}_{\mathrm{i}}\right]$ is copper concentration, $H$ is the Hill coefficient, $\left[\mathrm{Cu}_{0.5}\right]$ is the copper concentration at the midpoint of the response curve, calculated from the Hill plot, $Y_{\max }$ is the maximum $\beta$-galactosidase activity (in this case found by trial and error from determining which value gave the maximum correlation coefficent in a linear regression analysis) and $Y_{b}$ is the basal level of activity.

DNA sequence determination and analysis. DNA nucleotide sequence was determined with the Sequenase/ dideoxynucleotide method for dsDNA plasmid templates (USB) or with an ABI Cycle Sequencer for PCR-derived dsDNA templates, both according to the manufacturers' instructions. Sequence analysis was performed using the programs of the University of Wisconsin Genetics Computer Group (Devereux et al., 1984).

Transcription start points. In vivo transcription start points were detected by extension of the oligonucleotides D3006 (TTCGTCGAGACGTTTTCAAC) and D3007 (ACCCAAACAATCAATGGC) which are complementary to positions 272-291 and 6643-6660 of the pco sequence, respectively, hybridized against total cellular RNA (Debarbouille \& Raibaud, 1983). RNA was extracted by the hot acid phenol method (Aiba et al., 1981).

\section{RESULTS}

\section{Promoter regions and transcription start points}

Copper-dependent promoter activity in $p c o$ was identified by cloning a Sau3AI digest of pPA87 (Table 1) upstream of the promoterless lac $Z$ gene in the low-copy- number plasmid pMU2385 and seeking copperinducible lacZ $^{+}$colonies in E. coli TG2. Five such recombinants were found and DNA sequence analysis showed that they contained overlapping fragments from the region immediately upstream of $p c o E$ (Brown et al., 1995). Features of the pco sequence are summarized in Fig. 1. One of these clones, designated pMUE23 was used in later experiments.

The $p c o A B C D$ genes are known to be required for copper-inducible copper resistance (Brown et al., 1995) and the above results showed that the region upstream of $p c o E$ contained a copper-inducible promoter. Therefore PCR products of regions $5^{\prime}$ to both $p c o A$ and $p c o E$, of 291 and $272 \mathrm{bp}$, respectively, were cloned upstream of the promoterless cat gene in the medium-copy-number vector pKK232.8, giving plasmids $\mathrm{pA}$ and $\mathrm{pE}$ (Fig. 2a, b) and these conferred copper-inducible chloramphenicol resistance. For both the pMU2385 and pKK232.8 derivatives copper-inducible expression of the reporter genes was found whether or not pPA87 was present in trans, indicating that chromosomal genes also regulate the $p c o$ promoters.

Primer extension analysis was carried out to determine the transcriptional start points $5^{\prime}$ to both $p c o A$ and pcoE. RNA samples isolated from TG2 harbouring pPA173 (i.e. a complete $p c o$ determinant, Fig. 1) or one of the two PCR clones, pA (PpcoA) and pE (PpcoE), were used with the appropriate oligonucleotide primers. Fig. 3 shows that with copper induction, a single weak band was seen for PpcoA RNA from pA, while RNA from pPA173 gave a stronger band in the same position. This corresponds to nt A184 in the pco sequence (Brown et al., 1995), 82 bp upstream from the initiation codon of the $p c o A$ gene. With copper-depleted growth medium pPA173 showed a much weaker band at this point, showing transcription from this point was copperinducible. In the presence of copper pE RNA gave a strong signal, with two strong bands at nt A6556 and A6557, 127-128 bp upstream from the start of pcoE; these were preceded by four weaker bands at nt 6552-6555. With exposure to the same copper concentration the $\mathrm{P} p c o E$ promoter gave a much stronger signal than PpcoA, suggesting a higher level of transcription initiation. Quantification of the relative levels of RNA was not attempted, as residual copper ions in the preparations may have catalysed some RNA degradation.

Suitable -10 promoter elements were identified at the appropriate locations upstream of both transcription starts. These were similar to the $E$. coli consensus hexamer, being TAGATT $(\mathrm{P} p c o A)$ and a perfect consensus TATAAT (PpcoE). There were relatively weak fits to the -35 hexamer TTGACA, ATGAAT (PpcoA) and GCGATA $(\mathrm{P} p c o E)$ at 18 and $16 \mathrm{bp}$ spacing from their respective -10 elements (Fig. 2a, b). PpcoA contains an extended -10 element TGCTAGATT. Such a TGN sequence immediately before the -10 sequence is found in promoters which do not require specific RNA polymerase-DNA contacts in the -35 


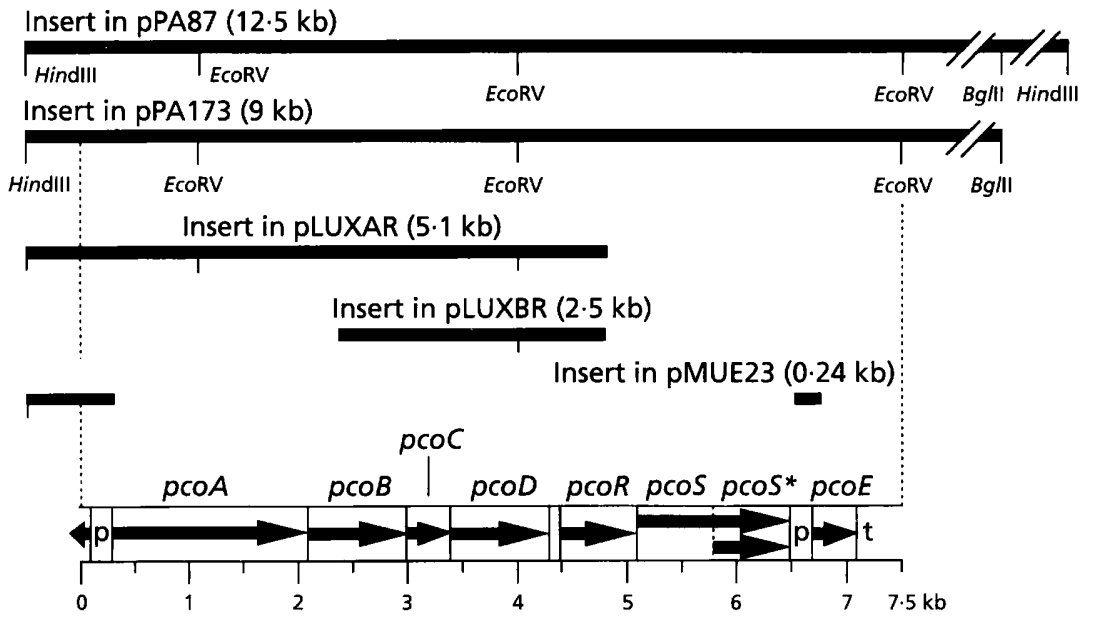

Fig. 1. Map of the pco determinant showing the location of large DNA fragments used in this work. The map is derived from the sequence (EMBL accession number $\mathrm{X} 83541$; Brown et al., 1995) and shows the structural genes pCOABCDRS(S*)E. p, Promoters $5^{\prime}$ to $p C O A$ (PpCOA) and pCOE (PpCOE); t, a putative $\rho$-independent transcription terminator.

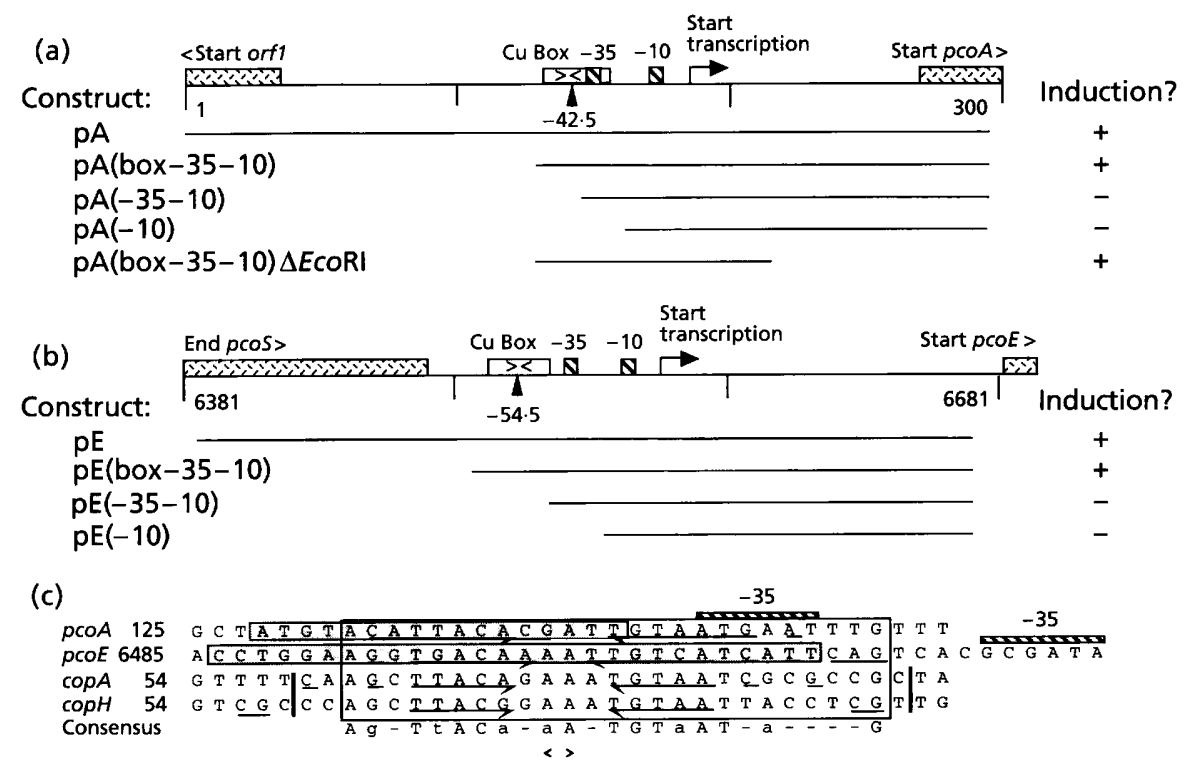

Fig. 2. PpCOA and PpCOE promoter regions. The locations of transcription start points, -10 and -35 promoter regions and copper boxes are shown, with the adjacent structural genes marked. Numbers given at the ends of the sequence maps (and in parentheses below) are pco sequence co-ordinates and correspond to the map in Fig. 1 (Brown et al., 1995). The copper-inducible expression of individual constructs is marked; details are shown in Fig. 4. (a) PpcoA region and constructs. pA, complete pcoA promoter with upstream sequences (1-291); pA(box-35-10), pcoA promoter containing copper box, -35 and -10 sequences (128-291); pA $(-35-10)$, pcoA promoter region lacking copper box (145-291); $\mathrm{pA}(-10)$, pcoA promoter region lacking copper box and -35 sequence (163-291); pA(box $-35-10) \triangle E c o R I, p c o A$ promoter containing copper box, -35 and -10 sequences truncated at the $3^{\prime}$ end (128-232). (b) PpcoE region and constructs. $\mathrm{pE}$, complete $p C O E$ promoter with upstream sequences (6388-6660); $\mathrm{pE}(\mathrm{box}-35-10)$, pcoE promoter containing copper box, -35 and -10 sequences $(6486-6660) ; \mathrm{pE}(-35-10)$, pcoE promoter region lacking copper box (6514-6660); $\mathrm{pE}(-10)$, pCoE promoter region lacking copper box and -35 sequence (6533-6660). (c) Alignment of nucleotide sequences in the upstream region of pco and cop promoters. The $E$. coli copper box (this study) and Pseudomonas cop box (Mills et al., 1994) regions are boxed. For each sequence the bases forming the inverted repeat are underlined and the common dyad centre is shown by arrowheads $(<>)$ below the sequences. The minimum essential regions for copper-inducible transcription for PpcoA and PpcoE identified from analysis of truncated promoters are shaded. The two vertical bars in the PcopA and PcopH sequences mark the extent of the DNase I footprint for CopR (Mills et al., 1994).

region (Kumar et al., 1993; Minchin \& Busby, 1993). In contrast, PpcoE does not contain such a sequence.

Inspection of the promoter regions for further similarities which might correspond to cis-acting copper control regions revealed a conserved 25 bp sequence containing a hyphenated dyad AxxTxACAxxATTGTxATxAxTxxG. It overlapped the -35 hexamer region in PpcoA (dyad centre at -42.5 relative to the start of trancription) and was $5^{\prime}$ to the -35 region in PpcoE 


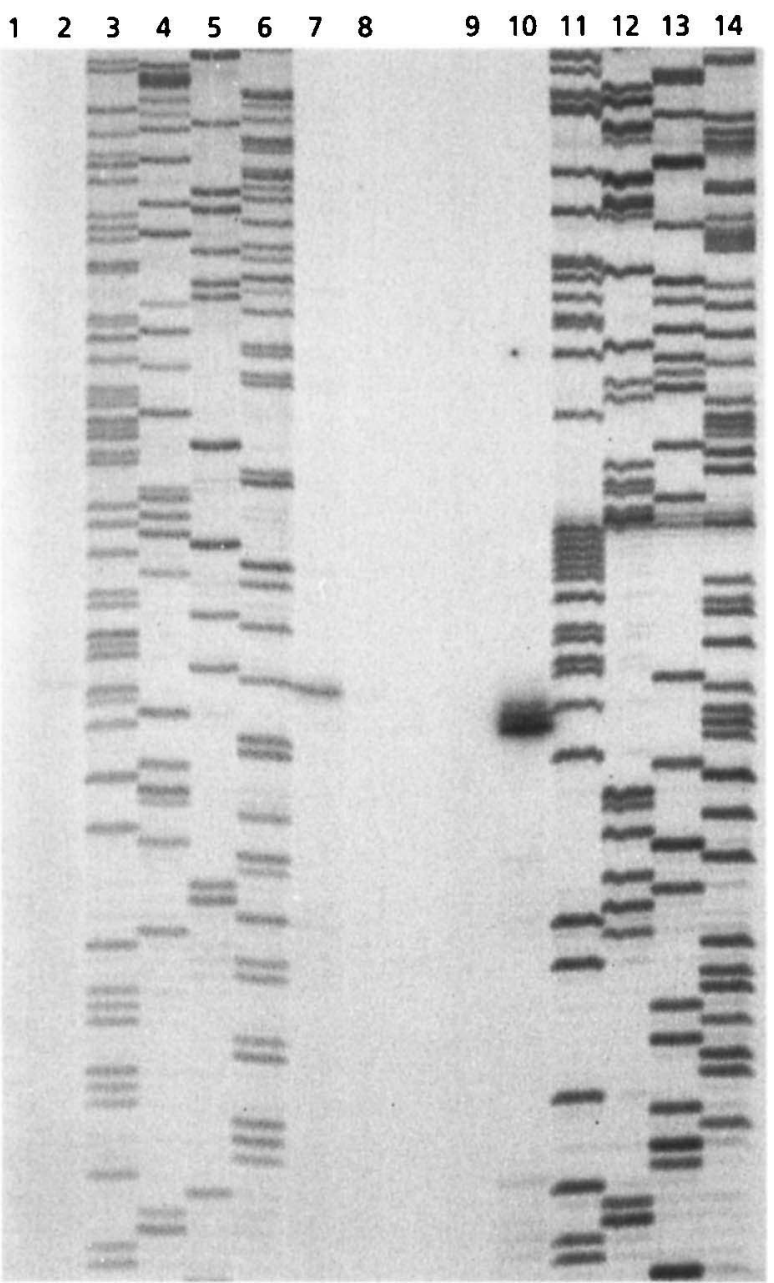

Fig. 3. Primer extension analysis for PpcoA and PpcoE RNA from cells grown with $(+)$ or without $(-) 0.8 \mathrm{mM}$ copper. Lanes 1-8, with primer D3006 (for PpcoA): 1, pKK232.8(+); 2, pA $(+)$; $3-6$, PpcoA sequence (TGCA); 7, pPA173(+); 8 , pPA173(-) Lanes 9-14, with primer D3007 (for PpCOE): 9, pKK232.8(+); 10, $\mathrm{pE}(+)$; 11-14, PpcoE sequence (TGCA). Exact transcriptional start points were deduced from shorter exposures than that shown here.

(dyad centre at $-54 \cdot 5$ ), bp 132-156 and 6492-6516, respectively (Fig. 2c). This motif is similar to sequences seen in the regions of plasmid $(\operatorname{cop} A)$ and chromosomal (copH) genes from P. syringae pv. tomato to which the CopR protein binds (Mills et al., 1994; Fig. 2c). The consensus of all four sequences is the $25 \mathrm{bp}$ motif AgxTtACaxa $<>$ AxTGTaATxaxxxxG (where $<>$ is the dyad centre). The motif is referred to as a 'copper box'.

\section{Are copper box sequences required for copper- inducible transcription?}

The function of the copper boxes was tested by cloning PCR products into the CAT reporter vector pKK232.8, to give transcriptional fusions. Three types of PCR product were used for each promoter region (Fig. 2 legend), having identical $3^{\prime}$ ends but varying in their $5^{\prime}$ ends, so that they contained (i) the copper box and -35 , -10 elements, (ii) only the -35 and -10 elements or (iii) only the -10 element (Fig. 2a, b). The various recombinant plasmids were assayed in vivo for metalinducible transcriptional activity by measurement of (a) the growth rate of transformants when challenged with chloramphenicol, (b) their MIC values for chloramphenicol and (c) CAT activity of cell extracts (Fig. 4). CAT assays provided the most direct measure of reporter activity, but the two growth assay methods proved to be more sensitive at low levels of induction.

Only plasmids containing intact copper boxes gave significant copper inducibility, while the $(-35-10)$ and $(-10)$ fragments gave weak constitutive responses (Fig. 4). Both PpcoE $(-35-10)$ and $(-10)$ fragments gave near background constitutive responses, while the $\mathrm{P} p c o A(-10)$ fragment (which contained the extended -10 sequence) gave a higher constitutive response, close to the value for the uninduced complete promoter region. The $\mathrm{PpcoA}(-35-10)$ construct also gave a constitutive response significantly above background in the MIC and growth rate tests. The CAT assays had relatively high errors at very low enzyme activities. The higher activities of the $\mathrm{P} p c o A(-10)$ and $\mathrm{Ppco} A(-35-10)$ constructs is consistent with the extended -10 motif in this promoter; similar elevated levels of transcription are observed in the E. coli gal operon P1 promoter (Chan \& Busby, 1989; Minchin \& Busby, 1993). Truncated promoters were also tested in MIC assays with the presence of plasmid-expressed PcoR and gave qualitatively similar results to those when it was absent (data not shown).

In the PpcoA $(-35-10)$ construct 12 bp of the copper box motif remains due to the overlap of the copper box and -35 regions. However, this construct still failed to exhibit inducible activity. This indicated that the $17 \mathrm{bp}$ region from bp 128 to 145 , which contained the $5^{\prime}$ half of the copper box motif in PpcoA, was necessary for induction. Correspondingly, for $\mathrm{P} p c o E$ the $28 \mathrm{bp}$ region from 6486 to 6514 , which contained $22 \mathrm{bp}$ of the $25 \mathrm{bp}$ copper box, was necessary for induction.

All three methods confirmed P $p c o E$ to be stronger than $\mathrm{P} p c o A$, with plasmids carrying both full-length and (box-35-10) fragments, with up to a 25 -fold difference in induced CAT activity. PpcoE also provided a higher level of constitutive activity in the absence of added copper sulphate. Zinc sulphate was also tested for regulatory activity in the MIC test and was found to give a small level of induction for both PpcoA and PpcoE in both complete and (box-35-10) form, but was only statistically significant for PpcoE (Fig. 4c, d). An attempt was made to test induction with silver ions, since $A g(I)$ is similar to $\mathrm{Cu}(\mathrm{I})$, but their toxicity at the necessary concentrations prevented cell growth.

The PpcoA minimal promoter fragment A (box $-35-10$ ) was further truncated at the $3^{\prime}$ end by removing DNA downstream of bp 232, 47 bp downstream of the transcription start, using the internal 

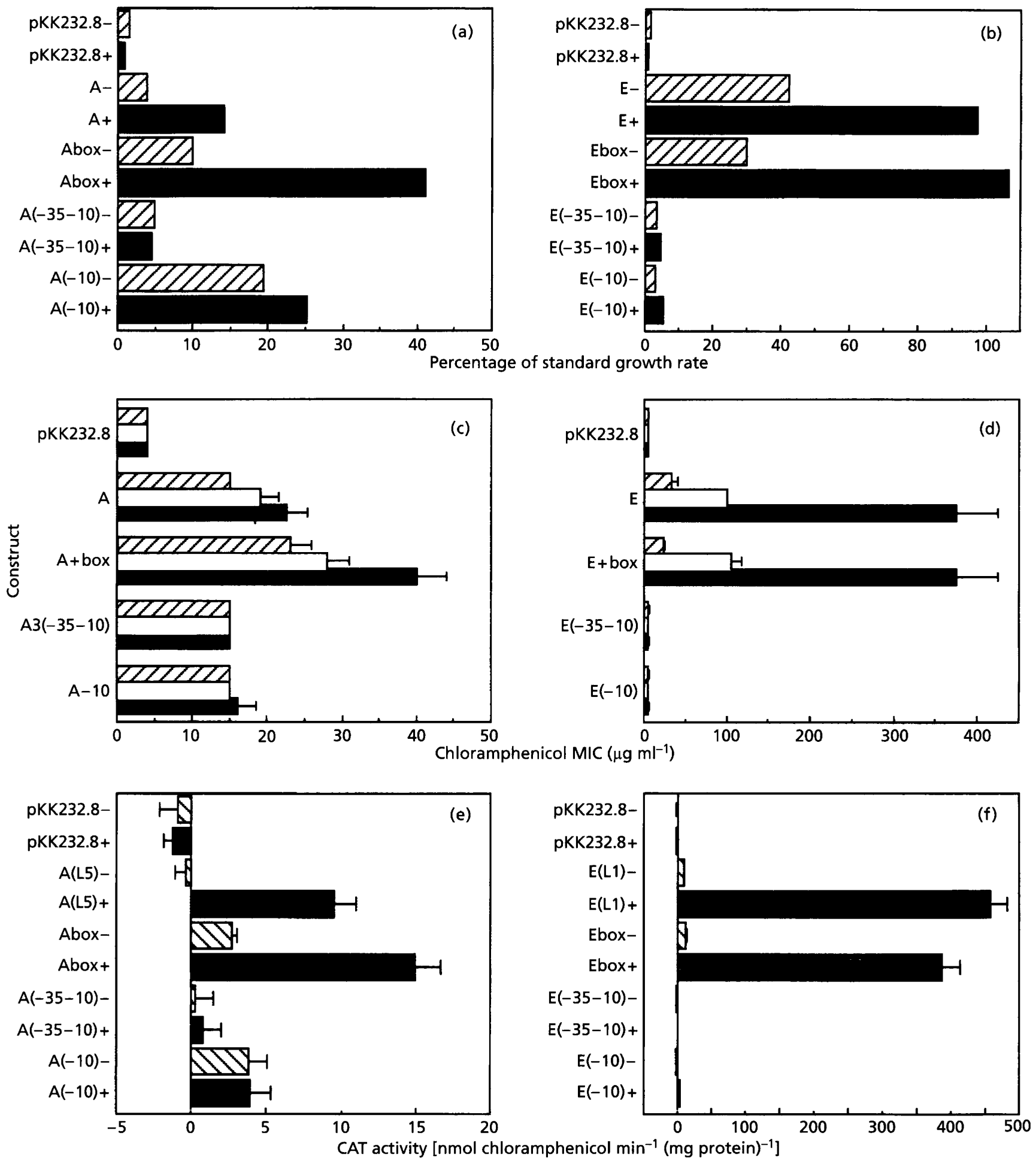

Fig. 4. Assays of wild-type and truncated promoters linked to the CAT reporter gene in pKK232.8. (a), (c) and (e) are PpCOA; (b), (d) and ( $f$ ) are PpCoE, with $(+)$ and without $(-)$ induction with copper; error bars are one SD. (a, b) Relative growth rates; (c, d) MIC measurements; $(e, f)$ CAT assays (compared to the host TG2 strain in the absence of plasmid as zero). The constructs used are summarized in the legend to Fig. 2 . In all cases the data bars are: hatched, uninduced; black, following induction with copper sulphate; white ( $c$ and d only), following induction with zinc sulphate.

EcoRI site. This 105 bp DNA, A(box $-35-10) \Delta E c o$ RI, retained copper-inducible transcription activity (data not shown).
Insertion of the A PCR product, pco bp 1-291, in pKK232.8 in the reverse orientation to $\mathrm{pA}$ revealed strong constitutive promoter activity divergently from 


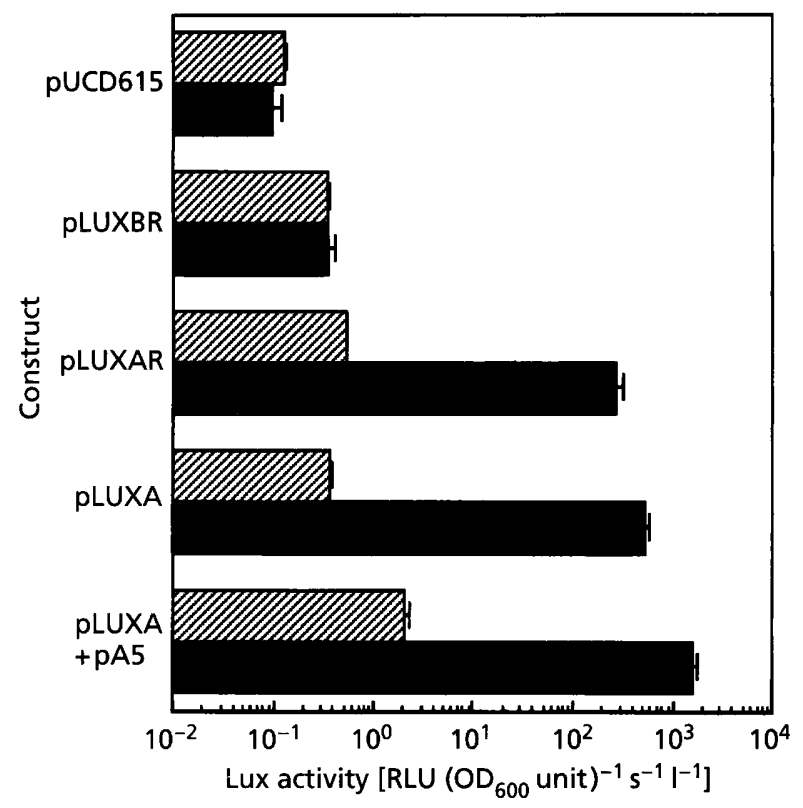

Fig. 5. Assays of pco::lux fusions in various plasmids as described in the text. Lux activity was measured in RLU output (Relative Light Units) per $\mathrm{OD}_{600}$ unit (cell density factor) per second per litre (sample volume); error bars are one SD. Activities were measured in the presence (black bars) or absence (hatched bars) of $0.6 \mathrm{mM} \mathrm{CuSO}_{4}$.

PpcoA. This may allow expression of an ORF of unknown function (see Fig. 2a).

\section{Expression of the pcoRS region}

While inducible control of the structural genes for copper resistance, initiated from $\mathrm{P} p c o A$ and $\mathrm{P} p c o E$, was consistent with their function, it was unclear if the transacting regulatory genes would be under similar control. The regulatory genes $p c o R S S^{*}$ form a distinct block within the pco determinant, with significant gaps between them and the flanking resistance genes (Fig. 1; Brown et al., 1995), which might allow separate expression. To assess transcription through $p c o R$ two pco-lux fusions were constructed by cloning into the lux vector pUCD615 (i) the segment from the HindIII site 5' to PpcoA to mid-pcoR (bp 4807), to form pLUXAR, and (ii) the segment from mid-pcoB to mid-pcoR (bp 2339-4807) to form pLUXBR. The lux system was used because of its simplicity and great sensitivity in detecting low levels of transcription, and because of its potential use in biotechnology. Fig. 5 shows the activities of these plasmids; pLUXAR exhibited strongly inducible lux activity, similar to that shown by pLUXA which contains the $\mathrm{P} p c o \mathrm{~A}(\mathrm{box}-35-10)$ fragment. In contrast, pLUXBR lacks Ppco $A$ and showed a low degree of constitutive activity, which was significantly greater than pUCD615 vector alone. Whether this is a result of a specific promoter or non-specific promotion is unclear. Either way, the result suggested that $p c o R S S^{*}$ could be transcribed at a low level in the absence of

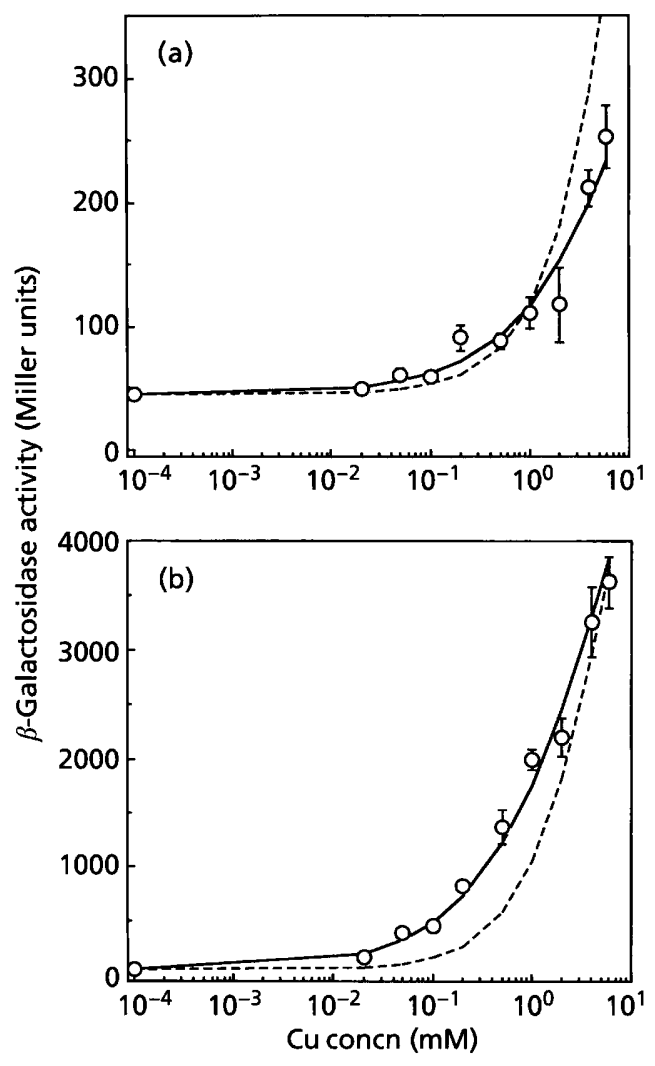

Fig. 6. Promoter response profiles across a range of copper concentrations. (a) PpcoA (pMUA); (b) PpcoE (pMUE). Both profiles have curves for Hill coefficients of 0.67 (full line) and 1.0 (dashed line) fitted.

induction at PpcoA. In addition, the detection of inducible transcription at $p c o R$, in pLUXAR, indicates that $p c o R S S^{*}$ can also be expressed from the PpcoA promoter; i.e. $p c o A B C D R S S^{*}$ can be transcribed as a unit. The idea that the $p c o R S S^{*}$ genes can be transcribed separately while a block transcript can arise from $\mathrm{P} p c o A$ is supported by complementation analysis of $\mathrm{Tn} 1000$ insertion mutants (Brown et al., 1995; Rouch et al., 1989). This showed that $p c o A B C D$ form a single complementation group separate from the regulatory genes.

\section{Response profiles of pco promoters}

The response profiles of $\mathrm{P} p c o A$ and $\mathrm{P} p c o E$ to a range of copper sulphate concentrations were assessed, with transcription from the minimal promoters (box $-35-10)$ fragments used to drive $\beta$-galactosidase reporter activity from the low-copy-number vector pMU2385 (Fig. 6). Curves were fitted to the data using the Hill equation, which assumes a response profile to be sigmoidal in shape. A standard Michaelis-Menten response gives a sigmoid with a Hill coefficient, $H$, of $1 \cdot 0$, while steeper and flatter responses have $H$ values greater or less than $1 \cdot 0$, respectively. Since no relative flattening of the responses for both $\mathrm{P} p c o A$ and $\mathrm{P} p c o E$ 
(a)

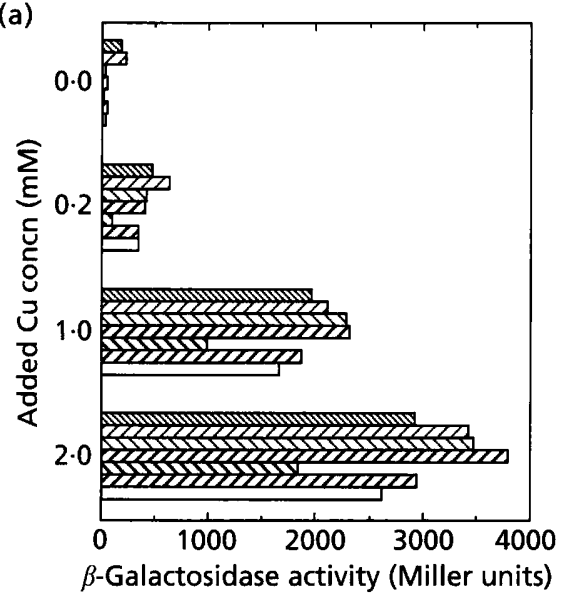

(b)

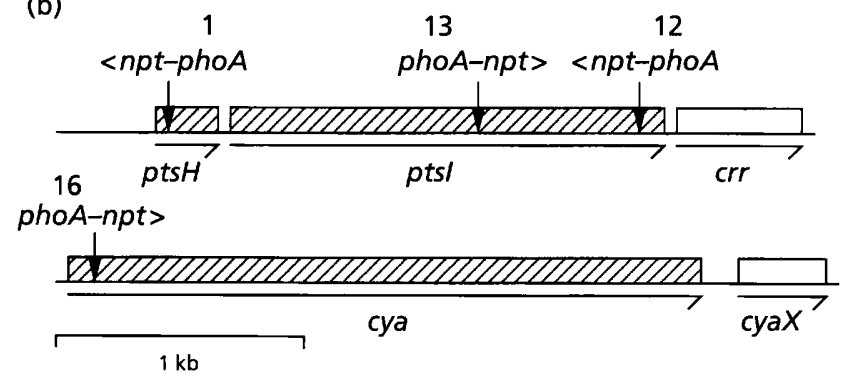

Fig. 7. (a) $\beta$-Galactosidase reporter activities of TnphoA mutants. Strains containing the reporter plasmid pMUE23 (PpcoE::lacZ) are shown for each copper concentration in the order (top to bottom): mutants 1, 12, 13, 14, 16, 17 and parental strain TG2; each assay is the mean of two independent measurements. (b) Location of TnphoA insertions in the $E$. coli pts and cya chromosomal regions (from EMBL database files ecphosys and eccya01, respectively). Half arrows show the gene orientations; arrows mark TnphoA insertions in the orientations shown.

was seen at the higher copper concentrations used, as expected for saturation of a sigmoidal response, it was assumed that these copper levels were not high enough to show flattening. Copper toxicity precluded the use of higher copper levels. Nevertheless, the calculated curves gave an acceptable fit to the data. Fig. 6(a) shows the response for PpcoA, fitted with a curve of $H=0 \cdot 67$. A curve with $H=1.0$ is given for comparison, demonstrating that PpcoA gives a shallower response than a standard Michaelis-Menten curve. Little change in promoter activity was seen for copper levels up to $0.02 \mathrm{mM}$, while above $0.1 \mathrm{mM}$ activity increased markedly with rising copper level.

As reported in separate experiments with $\mathrm{P} p c o E$ on a different DNA fragment (Mills et al., 1994), the data for PpcoE fitted with a $H$ value of $0 \cdot 67$, thus giving a response similar in shape to $\mathrm{P} p c o A$. However, the actual $\beta$-galactosidase activities for PpcoE were an order of magnitude higher than for $\mathrm{P} p c o A$. Both promoters gave similar basal levels in the absence of added copper,
$\mathrm{P} p c o A 45 \pm 0 \cdot 8$ and $\mathrm{P} p c o E 41 \pm 3$ units, but at $4 \mathrm{mM}$ copper they were $212 \pm 14$ and $3256 \pm 324$ units, respectively. The relative differences in strength of $\mathrm{P} p c o E$ and $\mathrm{P} p c o A$, as detected using the $\beta$-galactosidase reporter plasmid pMU2385, was similar to that seen with the CAT reporter plasmid pKK232.8 (Fig. 4).

\section{Investigation of chromosome-directed regulation}

To identify chromosomal genes affecting the regulation of $p c o$, TnphoA mutagenesis was performed with pMUE23 acting as the reporter plasmid. Mutants were screened for either a derepressed or super-repressed response, as judged by plate tests. From this initial screening of over 40000 transconjugants, six mutants were chosen for further study: numbers $1,12,13,14,16$ and $17 . \beta$-Galactosidase activity of the mutant strains containing pMUE23 was determined across a range of copper sulphate concentrations (Fig. 7a). Each mutant retained copper inducibility, but showed an altered response compared to wild-type. Mutants 1 and 12 were slightly derepressed in the absence of added copper and showed increased activity at all copper concentrations. Mutants 13, 14 and 17 showed increased reporter gene activity at low $(0 \cdot 0$ and $0.2 \mathrm{mM})$ added $\mathrm{CuSO}_{4}$, while 13 and 14 showed greater induction than wild-type at high $(1.0$ and $2.0 \mathrm{mM})$ added $\mathrm{CuSO}_{4}$. Mutant 16 alone showed a super-repressed phenotype. Furthermore, the additional presence of pPA256, which bears the $p c o$ regulatory genes $p c o R S S^{*}$, failed to restore wild-type reporter activity (data not shown). The six mutants all showed significantly enhanced copper tolerance, with MICs of $2.0 \mathrm{mM} \mathrm{CuSO}_{4}$ compared to $1.2 \mathrm{mM}$ for the parental strain and other TnphoA mutants.

The sites of $\operatorname{Tn} p h o A$ insertion were examined by sequencing of PCR products obtained by inverse PCR. Chromosomal sequence flanking the $5^{\prime}$ end of TnphoA was obtained for five mutants and used to search the EMBL and GenBank DNA sequence databases for similarities. Chromosomal DNA from four mutants, 1 , 12, 13 and 16, showed near identity to known E. coli DNA sequences, while the 316 bp sequence from mutant 17 remained unidentified. Sequences from mutant 14 could not be obtained. Three of the mutants, 1, 12 and 13 , had resulted from insertions in two genes specifying parts of the $p t s$ sugar phosphotransferase system, $p t s H$ and $p t s I$, while mutant 16 contained an insertion in the adenylate cyclase gene, cya.

\section{DISCUSSION}

The two copper-dependent promoters found within the $p c o$ determinant, $\mathrm{P} p c o A$ and $\mathrm{P} p c o E$, differ both in structure and relative activity. Both contain a conserved 25 bp copper box motif, of which at least the $5^{\prime}$ half was necessary for copper-dependent activity. The motif is located differently in each case: that for PpcoA is centred at -42.5 and that for $\mathrm{P} p c o E$ at -54.5 relative to the start of transcription. The related cop boxes identified in the plasmid-encoded cop operon and its 
chromosomal homologue from Pseudomonas syringae pv. tomato as binding sites for the regulatory protein CopR (Mills et al., 1994) are at position $-42 \cdot 5$. The CopR protein has a $28 \mathrm{bp}$ DNase I footprint on the top strand of the two Pseudomonas promoters, in vitro (Mills et al., 1994). The PcoR protein and its putative chromosomal homologue, CutR, are expected to recognize the copper box motifs in both PpcoA and PpcoE. The Pseudomonas promoter regions are otherwise different from the two E. coli promoters, possibly due to species differences in RNA polymerase action.

The centre of binding of the cAMP receptor protein (CRP) transcriptional activator at class II sites is at a similar position $(-41.5)$ to that for the copper box at $\mathrm{P} p c o$ A. Furthermore, $\mathrm{P} p c o A$ (though not $\mathrm{P} p c o E$ ) has an extended -10 promoter element, which is also found in the CRP-dependent gal operon P1 promoter (Chan \& Busby, 1989; Minchin \& Busby, 1993). This extended promoter element may account for the low-level transcriptional activity seen with the $\operatorname{Ppco} A(-10)$ and $(-35-10)$ constructs, since specific -35 contacts for RNA polymerase may not be required. PpcoE does not show such an extended -10 sequence and the $\mathrm{P} p c o E(-35-10)$ and $\mathrm{P} p c o E(-10)$ promoter constructs failed to show significant constitutive activity. These data support the importance of sequences upstream of the -35 region in $p c o$ promoter activity, in addition to the -10 elements.

PpcoE provides much stronger copper-dependent activation of transcription than $\mathrm{P} p c o A$, as judged by both the CAT and $\beta$-galactoside reporter studies, as well as by primer extension analysis. This may be accounted for in part by the different placement of the copper box in $\mathrm{P} p$ coE, at $-54 \cdot 5$. A placement this far $5^{\prime}$ to the start of transcription may allow for direct contact by PcoR/ CutR with RNA polymerase as the means of activation. The best studied class 2 receiver OmpR, a positive as well as negative regulator, also binds far upstream, at multiple sites for the ompF promoter, though its exact mode of regulation is unclear (Rampersaud et al., 1994, 1989). In contrast, sequences upstream of the copper box in both P pcoA and P pcoE appear unnecessary for induction of promoter activity.

The sequence differences between the PpcoA and $\mathrm{P} p c o E$ promoters may reflect the requirements for differential expression of the resistance genes. The $p c o A B C D$ genes are expressed on a polycistronic message from $\mathrm{P} p c o A$, which allows for stoichiometric production of the four components. The separate expression from $\mathrm{P} p c o E$ may allow for higher, non-stoichiometric production of $\mathrm{PcoE}$ compared to the other components, or enables its expression at lower copper concentrations. Consistent with this, the $p c o E$ gene has a codon usage typical of a highly expressed protein, in contrast to $p c 0 A B C D$ which do not (Brown et al., 1995). Thus, PcoE may act separately from PcoABCD at high copper concentrations. PcoE is a periplasmic protein (C. J. D. Yates \& N. L. Brown, unpublished) and it may be responsible for sequestering copper at low toxic copper concentrations before the $p c o A B C D$ operon is fully induced.
Two important requirements of a system for managing exposure of a cell to a trace element that is also toxic, such as copper, are: (1) the system is relatively specific for the particular trace element, since lack of specificity risks poor control of that and other similar metals; and (2) the system is regulated in such a way as to maintain cellular homeostasis for the trace element, as a deficiency would reduce growth and an excess is toxic. The specificity requirement was examined at the regulatory level by testing for inducibility of $\mathrm{P} p c o A E$ by zinc ions: $\mathrm{Zn}(\mathrm{II})$ is the most similar trace element to $\mathrm{Cu}$ (II). Zinc did cause some activation but at a very low level compared with that caused by copper at a similar concentration. In this case regulation was provided by the chromosomal system, so the presumptive CutRdependent regulatory mechanism has good specificity for copper.

The shape of the induction curve, derived from measuring promoter activities for a range of copper concentrations, has been predicted to be influenced by the requirement for homeostasis (Lee et al., 1990). For a metal that is required for growth, such as copper, very high or very low metal concentrations may be disadvantageous to cell growth, and a promoter expressing genes for metal resistance proteins is expected to be expressed proportionally to the concentration of the metal. The response of $\mathrm{P} p c o A$ - and $\mathrm{P} p c o E-l a c Z$ fusions to copper under chromosomal regulation by CutR do show gradual response profiles. These are flattened sigmoidal curves with apparent Hill coefficients of 0.67 , which give a relatively wide range over which an approximately proportional response to copper occurs, compared with the normal Michaelis-Menten response. The observation that the level of expression of pRJ1004 (pco)-mediated copper resistance is proportional to the external copper concentration (Rouch et al., 1985) is consistent with these reporter gene studies, although detailed analyses of the current data are complicated by the presence of both chromosomal and plasmid-borne regulatory systems.

In an attempt to inactivate the $c u t R$ gene, to allow PcoR activity to be examined alone, a number of insertion mutants were obtained that derepressed or hyperrepressed pco promoter activity. Interestingly, no mutations were identified in putative two-component regulatory genes, but in four other genes, $p t s H$ (PTS phospho-carrier protein), ptsI (PTS enzyme I) and cya (adenylate cyclase, catalysing cAMP production) and one unknown gene. The PTS system may therefore mediate the effects seen. The $p t s H I$ gene products are thought to interact with the CheA/CheY chemotaxis regulators (Titgemeyer, 1993), and there may be crosstalk with the presumptive CutR/CutS system. All mutants showed some inducibility and the presumptive primary response regulator, CutR, was not identified.

The dual control of the pco promoters by chromosomal and plasmid regulators indicates integration of $p c o$ expression with that of the cellular copper control systems. Furthermore, the shapes of the promoter 
response curves support the idea that expression of $p c o$ is regulated in such a way as to help maintain cellular copper homeostasis. Thus, the pco-encoded copper resistance system can be seen as an auxiliary copper control mechanism for the cell, which co-operates with the host cell copper management systems, to extend the range of environmental copper concentrations over which the cell can survive.

\section{ACKNOWLEDGEMENTS}

We are grateful to Barry Lee for discussion and to Carol Bender for communicating results prior to publication. This work was supported by the Medical Research Council, UK (grant G.8921751CB) and the Royal Society Small Grants Scheme. Automated DNA sequencing done by Alta Bioscience, The University of Birmingham, was on an ABI machine provided by the Wellcome Trust and the MRC. For computer support we thank staff at both the Academic Computing Service, the University of Birmingham, and SEQNET, Daresbury, UK.

\section{REFERENCES}

Aiba, H., Adhya, S. \& de Crombrugghe, B. (1981). Evidence for two functional gal promoters in intact Escherichia coli cells. J Biol Chem 256, 11905-11910.

Bartolomé, B., Jubete, Y., Martinez, E. \& de la Cruz, F. (1991). Construction and properties of a family of pACYC184-derived cloning vectors compatible with pBR322 and its derivatives. Gene $102,75-78$.

Bender, C. L. \& Cooksey, D. A. (1986). Indigenous plasmids in Pseudomonas syringae pv. tomato: conjugative transfer and role in copper resistance. $J$ Bacteriol 165, 534-541.

Brosius, J. \& Holy, A. (1984). Regulation of ribosomal RNA promoters with a synthetic lac operator. Proc Natl Acad Sci USA 81, 6929-6933.

Brown, N. L., Rouch, D. A. \& Lee, B. T. O. (1992). Copper resistance determinants in bacteria. Plasmid 27, 41-51.

Brown, N. L., Lee, B. T. O. \& Silver, S. (1993). Bacterial transport of and resistance to copper. In Metal Ions in Biological Systems, pp. 405-430. Edited by H. Sigel \& A. Sigel. New York: Marcel Dekker.

Brown, N. L., Barrett, S. R., Camakaris, J., Lee, B. T. \& Rouch, D. A. (1995). Molecular genetics and transport analysis of the copper-resistance determinant ( $p c o)$ from Escherichia coli plasmid pRJ1004. Mol Microbiol 17, 1153-1166.

Cervantes, C. \& Gutierrez-Corona, F. (1994). Copper resistance mechanisms in bacteria and fungi. FEMS Microbiol Rev 14, 121-137.

Chan, B. \& Busby, S. (1989). Recognition of nucleotide sequences at the Escherichia coli galactose operon P1 promoter by RNA polymerase. Gene 84, 227-236.

Cooksey, D. A. (1993). Copper uptake and resistance in bacteria. Mol Microbiol 7, 1-5.

Cooksey, D. A. (1994). Molecular mechanisms of copper resistance and accumulation in bacteria. FEMS Microbiol Rev 14, 381-386.

Daggett, P., Gherna, R. L., Pienta, P., Nierman, W., Jong, S., Hsu, H., Brandon, B. \& Alexander, M. (1982). American Type Culture Collection. Catalogue of Strains I. Rockville, MD: American Type Culture Collection.
Debarbouille, M. \& Raibaud, O. (1983). Expression of the Escherichia coli malPQ operon remains unaffected after drastic alteration of its promoter. J Bacteriol 153, 1221-1227.

Devereux, J., Haeberli, P. \& Smithies, O. (1984). A comprehensive set of sequence analysis programs for the VAX. Nucleic Acids Res $12,387-395$.

Hill, A. V. (1913). The combinations of haemoglobin with oxygen and with carbon monoxide. Biochem J 7, 471-480.

Kumar, A., Malloch, R. A., Fujita, N., Smillie, D. A., Ishihama, A. \& Hayward, R. S. (1993). The minus 35-recognition region of Escherichia coli sigma 70 is inessential for initiation of transcription at an 'extended minus 10 ' promoter. $J$ Mol Biol 232, 406-418.

Lee, B. T. O., Brown, N. L., Rogers, S., Bergemann, A., Camakaris, J. \& Rouch, D. A. (1990). Bacterial response to copper in the environment: copper resistance in Escherichia coli as a model system. In Metal Speciation in the Environment, pp. 625-632. Edited by J. A. C. Broekaert, S. Guçer \& F. Adams. Berlin: Springer-Verlag.

Lee, Y. A., Hendson, M., Panopoulos, N. J. \& Schroth, M. N. (1994). Molecular cloning, chromosomal mapping, and sequence analysis of copper resistance genes from Xanthomonas campestris pv. juglandis: homology with small blue copper proteins and multicopper oxidase. J Bacteriol 176, 173-188.

Manoil, C. \& Beckwith, J. (1985). TnphoA: a transposon probe for protein export signals. Proc Natl Acad Sci USA 82, 8129-8133.

Mellano, M. A. \& Cooksey, D. A. (1988). Induction of the copper resistance operon from Pseudomonas syringae. J Bacteriol 170, 4399-4401.

Miller, J. H. (1972). Experiments in Molecular Genetics. Cold Spring Harbor, NY : Cold Spring Harbor Laboratory.

Mills, S. D., Lim, C. K. \& Cooksey, D. A. (1994). Purification and characterization of CopR, a transcriptional activator protein that binds to a conserved domain (cop box) in copper-inducible promoters of Pseudomonas syringae. Mol Gen Genet 244, 341-351.

Minchin, S. \& Busby, S. (1993). Location of close contacts between Escherichia coli RNA polymerase and guanine residues at promoters either with or without consensus -35 region sequences. Biochem J 289, 771-775.

Ochman, H., Gerber, A. S. \& Hartl, D. L. (1988). Genetic applications of an inverse polymerase chain reaction. Genetics 120, 621-623.

Pao, G. M., Tam, R., Lipschitz, L. S. \& Saier, M. H., Jr (1994). Response regulators: structure, function and evolution. Res Microbiol 145, 356-362.

Parkinson, J. S. (1993). Signal transduction schemes of bacteria. Cell 73, 857-871.

Parkinson, J. S. \& Kofoid, E. C. (1992). Communication modules in bacterial signalling proteins. Annu Rev Genet 26, 71-112.

Praszkier, J., Wilson, I. W. \& Pittard, A. J. (1992). Mutations affecting translational coupling between the rep genes of an IncB miniplasmid. J Bacteriol 174, 2376-2383.

Rampersaud, A., Norioka, S. \& Inouye, M. (1989). Characterization of OmpR binding sequences in the upstream region of the ompF promoter essential for transcriptional activation. $J$ Biol Chem 264, 18693-18700.

Rampersaud, A., Harlocker, S. L. \& Inouye, M. (1994). The OmpR protein of Escherichia coli binds to sites in the ompF promoter region in a hierarchical manner determined by its degree of phosphorylation. J Biol Chem 269, 12559-12566. 
Rogowsky, P. M., Close, T. J., Chimera, J. A., Shaw, J. J. \& Kado, C. I. (1987). Regulation of the vir genes of Agrobacterium tumefaciens plasmid pTiC58. J Bacteriol 169, 5101-5112.

Rouch, D. A. (1986). Plasmid-mediated copper resistance in E. coli. PhD Thesis, The University of Melbourne, Australia.

Rouch, D., Camakaris, J., Lee, B. T. O. \& Luke, R. K. J. (1985). Inducible plasmid-mediated copper resistance in Escherichia coli. J Gen Microbiol 131, 939-943.

Rouch, D., Lee, B. T. O. \& Camakaris, J. (1989). Genetic and molecular basis of copper resistance in Escherichia coli. In Metal Ion Homeostasis: Molecular Biology and Chemistry, pp. 439-446. Edited by D. Winge \& D. Hamer. New York: Alan R. Liss.

Sambrook, J., Fritsch, E. F. \& Maniatis, T. (1989). Molecular Cloning : a Laboratory Manual. Cold Spring Harbor, NY: Cold Spring Harbor Laboratory.

Shaw, W. V. (1975). Chloramphenicol acetyltransferase from chloramphenicol-resistant bacteria. Methods Enzymol 43, 737-755.

Silver, S. (1992). Plasmid-determined metal resistance mechanisms. Plasmid Special Issue, 79.

Silver, S. \& Ji, G. (1994). Newer systems for bacterial resistances to toxic heavy metals. Environ Health Perspect 102, 107-113.

Silver, S., Lee, B. T. O., Brown, N. L. \& Cooksey, D. A. (1993). Bacterial plasmid resistances to copper, cadmium, and zinc. In Chemistry of Copper and Zinc Triads, pp. 38-53. Edited by A. J. Welch \& S. K. Chapman. London: The Royal Society of Chemistry.
Stall, R. E., Loschke, D. C. \& Jones, J. B. (1986). Linkage of copper resistance and avirulence loci on a self transmissible plasmid in Xanthomonas campestris pv. vesicatoria. Phytopathology 76, 240-243.

Taylor, R. K., Manoil, C. \& Mekalanos, J. J. (1989). Broad-hostrange vectors for delivery of $\operatorname{Tn} p h o A$ : use in genetic analysis of secreted virulence determinants of Vibrio cholerae. J Bacteriol 171, 1870-1878.

Tetaz, T. J. \& Luke, R. K. J. (1983). Plasmid-controlled resistance to copper in Escherichia coli. J Bacteriol 154, 1263-1268.

Titgemeyer, F. (1993). Signal transduction in chemotaxis mediated by the bacterial phosphotransferase system. $J$ Cell Biochem 51, 69-74.

Tseng, H. C. \& Chen, C. W. (1991). A cloned ompR-like gene of Streptomyces lividans 66 suppresses defective melC1, a putative copper-transfer gene. Mol Microbiol 5, 1187-1196.

Voloudakis, A. E., Bender, C. L. \& Cooksey, D. A. (1993). Similarity between copper resistance genes from Xanthomonas campestris and Pseudomonas syringae. Appl Environ Microbiol 59, 1627-1634.

Yanisch-Perron, C., Vieira, J. \& Messing, J. (1985). Improved M13 phage cloning vectors and host strains: nucleotide sequences of the M13mp18 and pUC19 vectors. Gene 33, 103-119.

Received 13 September 1996; revised 2 December 1996; accepted 5 December 1996. 